\title{
Superior mesenteric artery syndrome: a vicious cycle
}

\author{
Zheng Andrew Zhang
}

Department of General Surgery, Royal Melbourne Hospital, Melbourne, Victoria, Australia

\section{Correspondence to} Dr Zheng Andrew Zhang, andrew.zhang@mh.org.au

Accepted 24 September 2018

\section{DESCRIPTION}

A middle-aged cachectic woman with significant medical history of quadriplegia, chronic osteomyelitis, chronic obstructive pulmonary disease, kyphoscoliosis and malnutrition presented with 3 days of persistent nausea and vomiting, absolute constipation and increasing abdominal distention. She has had similar episodes in the recent past, which were milder in nature, and were diagnosed as gastroenteritis. She was hypotensive (blood pressure $86 / 60 \mathrm{~mm} \mathrm{Hg}$ ) and tachycardic $(130 \mathrm{bpm})$ on arrival, with a grossly distended abdomen and active vomiting. Initial blood tests detected hypokalaemia $(\mathrm{K}+$ of $3.0 \mathrm{mmol} / \mathrm{L})$, a raised white cell count of $23.4 \times 10^{9} / \mathrm{L}$ and features of acute kidney injury. A nasogastric tube was inserted and over a litre of bilious gastric contents was immediately aspirated.

A non-contrast CT scan of the abdomen and pelvis was performed (as the patient is allergic to iodine contrast), which demonstrated marked distension of the stomach and duodenum terminating abruptly where the third part of the duodenum crosses over the aorta (figure 1). The aortomesenteric distance was approximately $5 \mathrm{~mm}$, with an angle of approximately $11^{\circ}$ (figure 2). Radiologically, the findings were in keeping with a superior mesenteric artery (SMA) syndrome. ${ }^{1}$ Gross distention of the stomach, likely as a result of chronic obstruction, was further compressing and displacing the root of the mesentery along with the SMA, causing a vicious cycle which led to a high-grade small bowel obstruction (figures 1 and 3). Urgent upper gastrointestinal endoscopy was performed to rule out intraluminal causes of obstruction and insertion of a feeding nasojejunal tube. Due to severe malnutrition, the

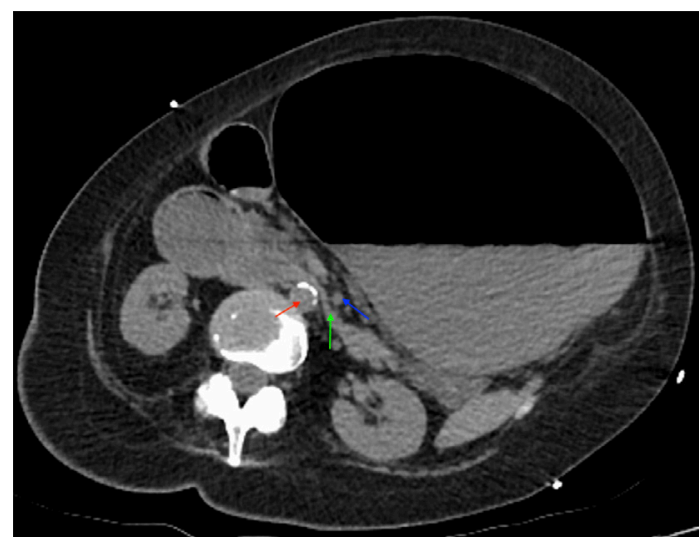

Figure 1 Axial CT abdomen demonstrating compression of the third part of the duodenum (green arrow) between the aorta (red arrow) and SMA (blue arrow). The grossly distended stomach is seen to further compress and displace the mesenteric root along with the SMA. SMA, superior mesenteric artery.

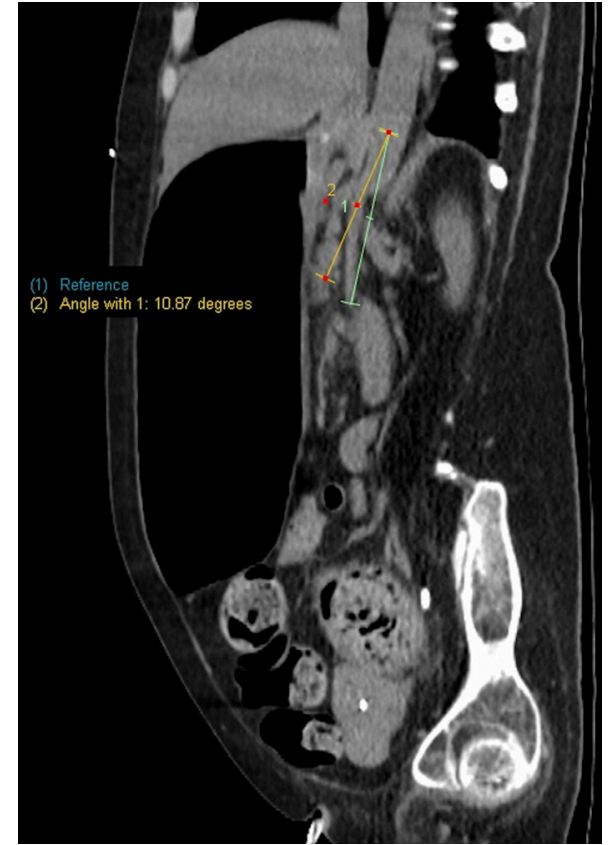

Figure 2 Sagittal CT abdomen demonstrating an aortomesenteric angle of approximately $11^{\circ}$.

patient was initially treated concurrently with both enteral and total parenteral nutrition with the aim of expediting recovery and optimising her nutritional state should she require surgery. An open gastrojejunostomy was performed when symptoms failed to improve after 2 weeks. The patient subsequently made an uneventful recovery.

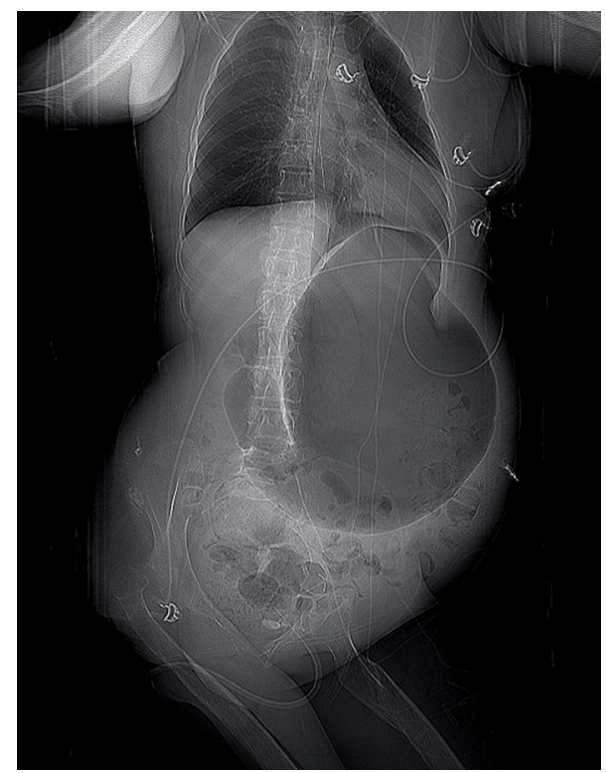

Figure 3 Grossly distended stomach on plain film. 
SMA syndrome is a rare condition characterised by extraluminal compression of the third part of the duodenum by the SMA and the abdominal aorta, attributed to the loss of mesenteric fat pad. Since its initial description in 1842, approximately 400 cases have been reported in the literature, and the incidence of the condition is unknown. ${ }^{2}$ The diagnosis is challenging due to the rarity of the disease and its non-specific symptoms, and often confused with other anatomical or motility-related causes of duodenal obstruction. Various risk factors can lead to a reduction of the mesenteric fat pad and decreased acuity between the aorta and the SMA, such as significant weight loss,

\section{Learning points}

- The majority of patients present with chronic abdominal symptoms including nausea and vomiting, postprandial abdominal pain and anorexia. The resulting weight loss further decreases the intervening space surrounding the duodenum.

- Chronic obstruction can result in significant distention of the stomach, which can trigger a vicious cycle where the mesenteric root along with the superior mesenteric artery is further displaced posteriorly, resulting in acute upper intestinal ileus. chronic illness, paraplegia and prolonged bed rest. ${ }^{2}$ Conservative management with nutritional support is advocated for patients who have a short clinical history, and patients with chronic symptoms are more likely to require surgical management if symptoms do not improve with nutritional support. ${ }^{3}$ There is no clear time limit for conservative management in the literature, though relief of symptoms has generally been observed from 2 to 12 days. $^{2}$ Surgical options for the treatment of SMA syndrome include Strong's procedure, gastrojejunostomy and duodenojejunostomy.

Contributors ZAZ diagnosed the patient and wrote this article.

Funding The authors have not declared a specific grant for this research from any funding agency in the public, commercial or not-for-profit sectors.

Competing interests None declared.

Patient consent Obtained.

Provenance and peer review Not commissioned; externally peer reviewed.

\section{REFERENCES}

1 Unal B, Aktaş A, Kemal G, et al. Superior mesenteric artery syndrome: CT and ultrasonography findings. Diagn Interv Radiol 2005;11:90.

2 Mandarry MT, Zhao L, Zhang C, et al. A comprehensive review of superior mesenteric artery syndrome. European Surgery 2010;42:229-36.

3 Merrett ND, Wilson RB, Cosman P, et al. Superior mesenteric artery syndrome: diagnosis and treatment strategies. J Gastrointest Surg 2009:13:287-92.

Copyright 2018 BMJ Publishing Group. All rights reserved. For permission to reuse any of this content visit http://group.bmi.com/group/rights-licensing/permissions.

BMJ Case Report Fellows may re-use this article for personal use and teaching without any further permission.

Become a Fellow of BMJ Case Reports today and you can:

- Submit as many cases as you like

- Enjoy fast sympathetic peer review and rapid publication of accepted articles

- Access all the published articles

- Re-use any of the published material for personal use and teaching without further permission

For information on Institutional Fellowships contact consortiasales@bmjgroup.com

Visit casereports.bmj.com for more articles like this and to become a Fellow 